\title{
Kombinasi Metode Pijat Woolwich dan Massage Rolling (punggung) Mempengaruhi Kecukupan ASI pada Ibu Post Partum
}

\author{
Hastuti Usman \\ Jurusan Kebidanan, Poltekkes Kemenkes Palu \\ Email Korespondensi: bid.hastuti@gmail.com
}

Article Info

Article history:

Submitted: 2019-02-21

Accepted: $2019-04-16$

Published: 2019-04-22

Keywords:

Woolwich Massage; Rolling Massage; Sufficiency of Breast Milk.
ABSTRACT

One of the failures of exclusive breastfeeding is the lack of a mother's level of confidence that her mother's milk cannot fulfill her baby's nutritional needs. Efforts that can be made to stimulate the hormone prolactin and oxytocin in the mother after childbirth is to provide a relaxed sensation in the mother by doing Woolwich massage and rolling massage (back). The purpose of this study was to determine the effect of a combination of Woolwich massage methods and Rolling Massage on Adequacy in post partum mothers. Research site in the Work Area of Mapane Health Center, Poso Regency. The type of research used was Quasi Experimental. Data analysis was performed by the chi squre test. The results of the study showed that $95.8 \%$ of the intervention group respondents had enough baby weight while in the group without intervention it was $70.8 \%$ with a value of $p=$ 0.048 . Frequency of BAK: $87.5 \%$ of respondents in the intervention group had sufficient frequency while in the group without intervention it was $45.8 \%$ with a value of $p=0.006$. BAB frequency in the intervention group $100 \%$ frequency is sufficient while in the group without intervention is $91.7 \%$ with a value of $p$ $=0.015$. This research is expected to be applied by midwives and taught to mothers and families to increase ASI production so that the coverage of exclusive breastfeeding is achieved in the area of the Research Health Center.

\section{PENDAHULUAN}

Pemberian ASI Eksklusif sudah dibuktikan secara ilmiah dapat memenuhi kebutuhan nutrisi bayi, oleh sebab itu Organisasi Kesehatan Dunia (WHO) merekomendasikan agar setiap bayi baru lahir mendapatkan ASI eksklusif selama enam bulan. ${ }^{1}$ Program ASI eksklusif cukup sulit dikembangkan karena berkaitan dengan berbagai permasalahan sosial di masyarakat. Banyak penyebab ketidakberhasilan pemberian ASI eksklusif ini, salah satu alasan adalah ibu kurangnya tingkat kepercayaan diri ibu bahwa ASI yang dimiliki dapat mencukupi kebutuhan nutrisi bayinya. ${ }^{2}$ Cakupan bayi baru lahir yang mendapat IMD sebesar $51,9 \%$ yang terdiri dari $42,7 \%$ mendapatkan IMD dalam $<1$ jam setelah lahir, dan $9,2 \%$ dalam satu jam atau lebih, tertinggi di Provinsi DKI Jakarta (73\%) dan terendah Bengkulu (16\%). Cakupan bayi 0-5 bulan yang masih mendapat ASI eksklusif sebesar $54,0 \%$, sedangkan bayi yang telah mendapatkan ASI eksklusif sampai usia enam bulan adalah sebesar $29,5 \% .^{3}$

Data Sulawesi Tengah Cakupan bayi 0-6 bulan yang masih mendapat ASI eksklusif yaitu 43,3\%. ${ }^{4}$ Kabupaten Poso tahun 2015 cakupan ASI esklusif $54 \%$ dan tahun 2016 yaitu 56\%. 5,6 Data Puskesmas Mapane tahun 2015 yaitu $46 \%$ dan tahun 2016 sebesar 48,9\%.,8 Dalam kondisi yang penuh kekhawatiran dan tidak 
percaya diri karena merasa ASI nya tidak cukup, ibu memerlukan bantuan dan dukungan untuk dapat mempertahankan produksi ASI. Dengan rasa tidak percaya diri dan kekhawatiran akan menyebabkan terhambatnya pengeluaran hormon oksitosin. Hormon oksitosin berdampak pada pengeluaran hormon prolaktin sebagai stimulasi produksi ASI pada ibu selama menyusui. ${ }^{9-11}$

Salah satu upaya yang bisa dilakukan untuk merangsang hormon prolaktin dan oksitosin pada ibu setelah melahirkan adalah memberikan sensasi rileks pada ibu dengan melakukan pijat woolwich. Cara melakukan pijat woo/wich yaitu pemijitan melingkar menggunakan kedua ibu jari pada area sinus laktiferus tepatnya $1-1,5 \mathrm{~cm}$ diluar areola mamae selama 15 menit yang akan merangsang sel saraf pada payudara, diteruskan ke hipotalamus dan direspon oleh hipofisis anterior untuk mengeluarkan hormon prolaktin yang akan dialirkan oleh darah ke sel mioepitel payudara untuk memproduksi ASI. Manfaat pemijatan metode woolwich adalah meningkatkan pengeluaran ASI, meningkatkan sekresi $\mathrm{ASI}$ dan mencegah peradagan payudara atau mastitis. ${ }^{12}$

Massage rolling punggung adalah pemijatan pada tulang belakang (costae 5-6 sampai scapula dengan gerakan memutar) yang dilakukan pada ibu setelah melahirkan untuk membantu kerja hormon oksitosin dalam pengeluaran ASI, mempercepat syaraf parasimpatis menyampaikan sinyal ke otak bagian belakang untuk merangsang kerja oksitosin dalam mengalirkan ASI agar keluar, tindakan ini dapat memengaruhi hormone prolaktin yang berfungsi sebagai stimulus produksi ASI pada ibu selama menyusui, selain itu dapat membuat rileks pada ibu dan melancarkan aliran syaraf serta saluran ASI pada kedua payudara. ${ }^{9}$ Penelitian Desmawati didapatkan hasil bahwa ibu postpartum yang dilakukan yang diberi intervensi kombinasi areola massage dengan rolling massage mempunyai peluang 5,146 kali untuk terjadi pengeluaran ASI kurang dari 12 jam postpartum. ${ }^{12}$ Kombinasi metode pijat woolwich dan massage rolling yang diberikan pada ibu postpartum sebanyak 2 kali/ hari diwaktu pagi dan sore selama 3 hari postpartum dimungkinkan akan dapat meningkatkan pengeluaran dan produksi ASI. Tujuan penelitan adalah mengetahui pengaruh kombinasi metode Pijat woolwich dengan massage rolling (punggung) terhadap kecukupan ASI pada ibu postpartum di Wilayah Kerja Puskesmas Mapane Kabupaten Poso.

\section{METODE PENELITIAN}

Penelitian ini menggunakan rancangan Static-Group Comparison dengan pendekatan Quasi Eksperimental. Variabel penelitian ini terdiri dari variabel independent Kombinasi Pijat Woolwich dan Massage Rolling (punggung) dan variabel independent Produksi Asi pada lbu Post Partum. Populasi yaitu semua ibu postpartum primigravida hari pertama yang melahirkan di Wilayah Kerja PKM Mapane pada bulan September sampai dengan November 2018. Pengambilan sampel menggunakan consecutive sampling dengan jumlah 48 orang.

Teknik pengumpulan dengan menggunakan data sekunder data di didapatkan dari bidan untuk mengetahui jumlah ibu post partum di wilayah puskesmas Mapane, data primer dilakukan pengukuran berat badan bayi, frekuensi BB dan BAK dari dua kelompok yaitu kelompok intervensi dan observasi, kelompok intervensi adalah ibu yang diberikan kombinasi Pijat Woolwich dan Massage Rolling (punggung) pada hari pertama post partum sampai hari ke 3, kemudian diukur produksi ASI pada hari ke-3, 4 dan 7 dan kelompok observasi adalah ibu post partum yang tidak diberikan intervensi apapun kemudian dilakukan observasi pengeluaran ASI pada hari hari ke3, 4 dan 7. Analisis data menggunakan chi squre 


\section{HASIL PENELITIAN}

Penelitian telah dilakukan pada 48 orang sampel yang telah memenuhi kriteria inklusi dan eklusi

Analisis Univariat

Tabel 1. Distribusi Frekuensi Berdasarkan Umur Ibu, Pendidikan dan Pekerjaan kelompok control dan intervensi di Wilayah Kerja Puskesmas Mapane

\begin{tabular}{lrc}
\hline Variabel & Frekuensi & Persentase (\%) \\
\hline Umur Ibu & & \\
20-35 tahun & 45 & 93,8 \\
>35 tahun & 3 & 6,3 \\
Pendidikan & & \\
SMP & 3 & 6 \\
SMA & 38 & 79 \\
Diploma & 5 & 10 \\
PT & 2 & 4 \\
Pekerjaan & & \\
IRT & 42 & 88 \\
PNS & 5 & 42 \\
Honorer & 1 & 2 \\
\hline Sumber: Data primer, 2018 &
\end{tabular}

Tabel 1. menunjukkan bahwa sebagian besar responden berumur 20-35 tahun (93,8\%), pendidikan responden terbanyak adalah SMA (79\%), dan memiliki pekerjaan terbanyak yaitu IRT (88\%).

Analisis Bivariat

Tabel 2. Kombinasi Metode Pijat Woolwich dengan Massage Rolling (punggung) terhadap Kecukupan ASI Wilayah Kerja Puskesmas Mapane

\begin{tabular}{|c|c|c|c|c|c|}
\hline \multirow{3}{*}{ Variabel } & \multicolumn{4}{|c|}{ Kelompok perlakuan } & \multirow{3}{*}{ Nilai $p$} \\
\hline & \multicolumn{2}{|c|}{$\begin{array}{c}\text { Woolwich dan } \\
\text { Massage Rolling }\end{array}$} & \multicolumn{2}{|c|}{ Tanpa Intervensi } & \\
\hline & $\mathbf{n}$ & $\%$ & $\mathbf{n}$ & $\%$ & \\
\hline \multicolumn{6}{|l|}{ Berat Badan } \\
\hline Cukup & 23 & 95,8 & 17 & 70,8 & $p=0,048$ \\
\hline Kurang & 1 & 4,2 & 7 & 29,2 & \\
\hline \multicolumn{6}{|l|}{ Frekuensi BAK } \\
\hline Cukup & 21 & 87,5 & 11 & 45,8 & $p=0,006$ \\
\hline Kurang & 3 & 12,5 & 13 & 54,2 & \\
\hline \multicolumn{6}{|l|}{ Frekuensi BAB } \\
\hline Cukup & 24 & 100 & 22 & 91,7 & $p=0,015$ \\
\hline Kurang & 0 & 0 & 2 & 8,3 & \\
\hline
\end{tabular}

Sumber: Data primer, 2018

Tabel 2 menunjukan bahwa 95,8\% responden kelompok intervensi memiliki berat badan bayi cukup sedangkan pada kelompok tanpa intervensi sebesar $70,8 \%$. Berdasarkan uji chisquare diperoleh nilai $p=0,048$ yang berarti ada pengaruh pemberian intervensi terhadap penambahan berat badan bayi. $87,5 \%$ responden kelompok intervensi memiliki frekuensi cukup sedangkan pada 
kelompok tanpa intervensi sebesar 45,8\%. Berdasarkan uji chisquare diperoleh nilai $p=0,006$ yang berarti ada pengaruh pemberian intervensi terhadap frekuensi BAK bayi. $100 \%$ responden kelompok intervensi memiliki frekuensi cukup sedangkan pada kelompok tanpa intervensi sebesar 91,7\%. Berdasarkan uji chisquare diperoleh nilai $p=0,015$ yang berarti ada pengaruh pemberian intervensi terhadap frekuensi BAB bayi.

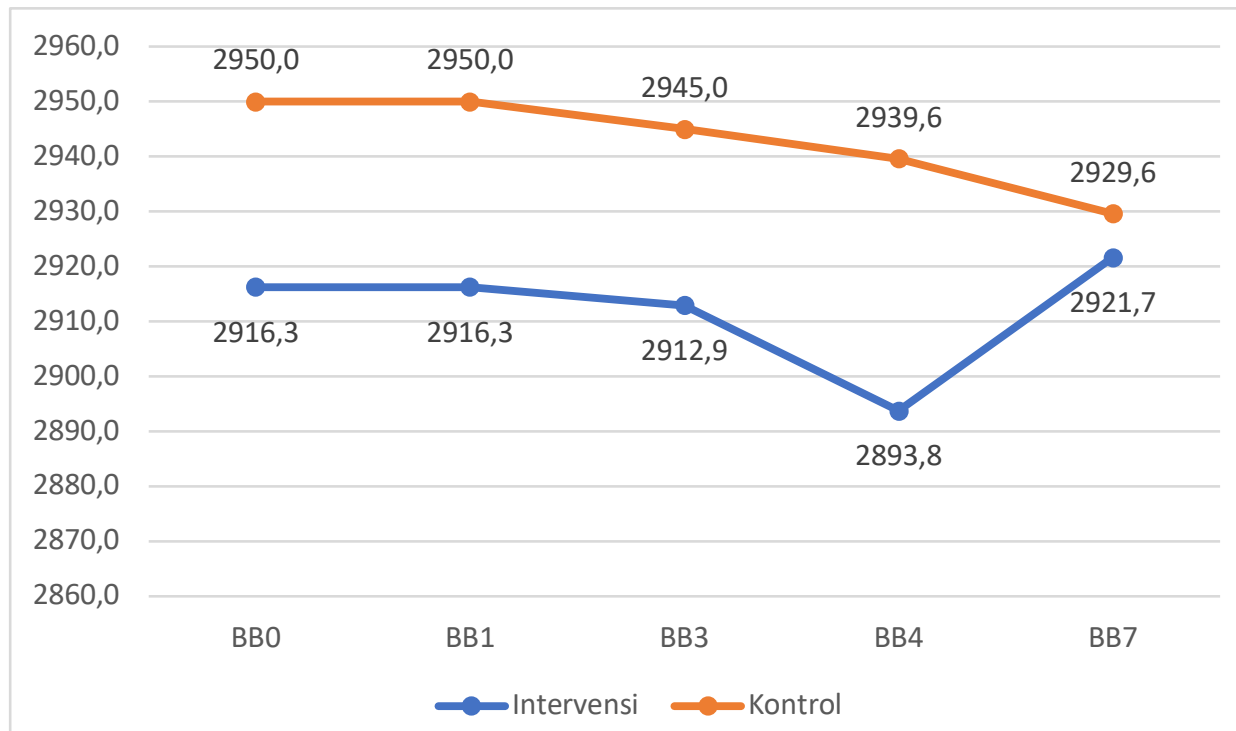

Grafik.1 Pertambahan berat badan bayi pada kelompok kontrol dan kelompok intervensi di Wilayah Kerja Puskesmas Mapane

Berdasarkan grafik di atas terlihat bahwa dari hari 0 sampai ke 4 berat badan bayi cenderung mengalami penurunan, untuk kelompok kontrol rerata berat badan mengalami penurunan sampai hari ke-7, sedangkan kelompok intervensi berat badan bayi mengalami peningkatan di hari ke-7.

\section{PEMBAHASAN}

Setelah melewati proses persalinan, Ibu Post Partum akan mengalami kelelahan, hal ini akan berpengaruh pada pengeluaran hormone oksitosin. Dalam proses laktasi selain hormone oksitosi dan prolaktin, faktor kesulitan bayi dalam mengisap, kurangnya tingkat kepercayaan diri ibu bahwa ASI yang dimiliki dapat mencukupi kebutuhan nutrisi bayi, dan keadaan putting susu ibu serta kurangnya rangsangan dapat mempengaruhi kelancaran pengeluaran ASI dan akibatnya kebutuhan nutrisi bayi tidak akan terpenuhi. 1,13

Pijat di daerah punggung belakang merupakan cara untuk merangsang pengeluaran hormone oksitosin agar keluar lebih banyak, Pijat ini berfungsi untuk memberikan rasa nyaman pada ibu menyusui pasca melahirkan serta meningkatkan produksi ASI Tindakan massage rolling punggung dapat memengaruhi hormon prolaktin yang berfungsi sebagai stimulus produksi ASI pada ibu selama menyusui. Tindakan ini juga dapat membuat rileks pada ibu dan melancarkan aliran syaraf serta saluran ASI pada kedua payudara. ${ }^{14}$ Tujuan Pijat Woolwich adalah memicu rangsangan sel-sel mioepitel di sekitar kelenjar payudara, kemudian rangsangan tersebut menuju ke hipotalamus dan dapat memicu hipofisis anterior untuk memproduksi hormon prolaktin. ${ }^{15}$ 
Back Rolling massage adalah pemijatan pada tulang belakang (costae 5-6 sampai scapula dengan gerakan memutar) yang dilakukan pada ibu setelah melahirkan untuk membantu kerja hormon oksitosin dalam pengeluaran ASI, mempercepat syaraf parasimpatis menyampaikan sinyal ke otak bagian belakang untuk merangsang kerja oksitosin dalam mengalirkan ASI agar keluar. ${ }^{12}$ Selain itu tindakan ini dapat membuat ibu rileks sehingga merangsang pengeluaran hormon prolaktin yang berfungsi melancarkan aliran syaraf serta saluran ASI pada kedua payudara. ${ }^{9}$

Kombinasi Pijat woolwich massage dan back rolling massage merupakan penggabungan dua metode yaitu pemijatan pada payudara lewat pemberian rangsang terhadap otot-otot buah dada dan punggung ibu, yang bertujuan memberikan rangsangan kepada kelenjar air susu ibu agar dapat memproduksi susu dan memicu hormon oksitosin atau refleks let down serta memberikan kenyamanan dan menciptakan rasa rileks pada ibu sehingga mengakibatkan produksi ASI meningkat.

Penilaian produksi ASI bisa dilihat dari beberapa faktor, di antaranya adalah tanda-tanda kecukupan ASI pada bayi. ASI cukup atau tidak bisa dilihat dari indikator Berat Badan Bayi, Frekuensi BAK dan BAB, di mana indikator ini juga merupakan indikator dari cukup atau tidaknya produksi ASI. Berdasarkan hasil penelitian pada tabel 2 menunjukkan bahwa ada pengaruh metode pijat woolwich dengan massage rolling (punggung) terhadap Produksi Asi yang dapat dibuktikan dengan Berat Badan Bayi cukup $(p=0,048)$, Frekuensi BAK cukup $(p=0,006)$ dan Frekuesi BAB cukup $(p=0,489)$. Patel (2013) menunjukkan bahwa efek pijat punggung terhadap proses laktasi selama masa nifas didapatkan terjadi peningkatan produksi ASI dengan menggunakan parameter berat badan bayi, jumlah BAK dan waktu istirahat bayi. Penelitian lain menunjukkan bahwa ada hubungan antara perawatan payudara pada ibu postpartum dengan kelancaran pengeluaran ASI. ${ }^{16}$

Dalam penelitian ini mayoritas keseluruhan responden adalah umur 20-35 tahun $(93,8 \%)$ menurut Biancuzo (2003) wanita dengan usia 20-35 tahun mempunyai produksi asi lebih banyak dari ibu-ibu yang usianya lebih dari 35 tahun. ${ }^{17}$ Hasil penelitian pada Garfik. 1 menunjukkan bahwa berat badan dari hari 0 sampai ke 4 berat badan bayi cenderung mengalami penurunan, untuk kelompok kontrol rerata berat badan mengalami penurunan sampai hari ke-7, sedangkan kelompok intervensi berat badan bayi mengalami peningkatan di hari ke-7. Secara teori, beberapa hari setelah lahir berat badan bayi akan turun $5-10 \%$ dari berat badan lahir. Hal ini normal terjadi karena bayi akan kehilangan cairan dan asupan ASI pada harihari pertama belum maksimal sehingga penelitian ini membuktikan bahwa kombinasi Pijat woolwich massage dan back rolling massage dapat meningkatkan produksi ASI ibu postpartum. Metode ini dapat diterapkan dan dapat meningkatkan pemberian ASI pada satu jam pertama kelahiran bahkan pemberian ASI esklusif.

\section{SIMPULAN DAN SARAN}

Ada pengaruh kombinasi metode pijat woolwich dengan massage rolling (punggung) terhadap produksi asi pada ibu post partum di Wilayah Kerja Puskesmas Kerja Mapane Kabupaten Poso. Penelitian ini menyerankan Intervensi kombinasi metode pijat woolwich dan message rolling (punggung) dapat dilakukan oleh bidan pada saat kunjungan rumah sehingga dapat meningkatkan pelayanan kebidanan pada ibu nifas serta mengajarkan keluarga dan menganjurkan ibu serta keluarga untuk tetap melaksanakan intervensi kombinasi metode pijat woolwich dan message rolling 
(punggung) sehingga dapat meningkatkan produksi ASI dan dapat memberikan ASI esklusif pada bayinya.

\section{DAFTAR PUSTAKA}

1. Roesli U. Inisiasi Menyusu Dini Plus ASI Eksklusif. Jakarta: Pustaka Bunda; 2008.

2. Roesli U. ASI Eksklusif. Jakarta: Pustaka Bunda; 2009.

3. Kementerian Kesehatan R.I. Profil Kesehatan Indonesia Tahun 2016. Jakarta: Kementerian Kesehatan R.I.; 2017.

4. Dinas Kesehatan Propinsi Sulawesi Tengah. Cakupan Pemberian ASI Eksklusif Sulawesi Tengah 2016. Palu; 2017.

5. Dinas Kesehatan Kabupaten Poso. Cakupan Pemberian ASI Eksklusif Kabupaten Poso Tahun 2016. Poso; 2017.

6. Dinas Kesehatan Kabupaten Poso. Cakupan Pemberian ASI Eksklusif Kabupaten Poso Tahun 2015. Poso; 2016.

7. Puskesmas Mapane. Cakupan Pemberian ASI Eksklusif Wilayah Kerja Puskesmas Mapane Tahun 2016. Poso; 2017.

8. Puskesmas Mapane. Cakupan Pemberian ASI Eksklusif Wilayah Kerja Puskesmas Mapane Tahun 2015. Poso; 2016.

9. Amin RM, Jaya H. Efektifitas Massage Rolling (punggung) terhadap produksi ASI pada Ibu Post SEctio Caesaria di RS Muhammadiyah Palembang. J Keperawatan. 2011;2(1).

10. Ari Shanti EF. Efektifitas Produksi ASI pada Ibu Post Partum dengan Massage Rolling (Punggung). Midwifery J J Kebidanan UM Mataram [Internet]. 31 Januari 2018;3(1):76. Tersedia pada: http://journal.ummat.ac.id/index.php/MJ/article/view/152

11. Badrus AR. Perbedaan Massage Woolwich dan Massage Rolling (Punggung) terhadap Peningkatan Produksi Asi pada Ibu Postpartum. J-HESTECH (Journal Heal Educ Sci Technol [Internet]. 13 Agustus 2018;1(1):43. Tersedia pada: http://ejournal.unitomo.ac.id/index.php/jhest/article/view/1081

12. Desmawati D. Penentu Kecepatan Pengeluaran Air Susu Ibu setelah Sectio Caesarea. Kesmas Natl Public Heal J [Internet]. 1 Maret 2013;7(8):360. Tersedia pada: http://journal.fkm.ui.ac.id/kesmas/article/view/22

13. Fraser DM, Cooper MA. Myles Buku Ajar Bidan. 14 ed. Jakarta: EGC; 2011.

14. Behrman, Kliegman, Arvin. IImu Kesehatan Anak. 15 ed. Wahab AS, editor. Jakarta: EGC; 2000.

15. Pamuji SEB. Pengaruh Kombinasi Metode Pijat Woolwich dan Endorphine Terhadap Kadar Hormon Prolaktin dan Volume ASI (Studi Pada Ibu Postpartum Di Griya Hamil Sehat Mejasem Kabupaten Tegal). Iniversitas Diponegoro; 2014.

16. Safitri I. Faktor-faktor yang Mempengaruhi Kelancaran Produksi ASI pada Ibu Menyusui di Desa Bendan, Kecamatan Banyudono, Kabupaten Boyolali [Internet]. Universitas Muhammadiah Surakarta; 2016. Tersedia pada: http://eprints.ums.ac.id/47378/

17. Biancuzzo M. Breastfeeding the Newborn: Clinical Strategies for Nurses. 2 ed. St. Louis: Gold Standard Publishing; 2002. 